\title{
El mapa del cine temprano en Chile: hacia una configuración del asombro en el contexto latinoamericano
}

\author{
The map of early cinema in Chile: Towards a \\ configuration of wonder in the \\ Latin American context
}

\author{
Mónica Villarroel Márquez \\ Universidad de Chile, Chile \\ monicavillarroelm@gmail.com
}

- Resumen - La llegada del cine a América Latina, y a Chile en particular, permite componer un mapa del cine temprano a este lado del mundo. Este artículo pretende avanzar en la configuración de un panorama del momento en que se conocieron las tecnologías cinematográficas disponibles a fines del siglo XIX, así como el modo en que fueron nombradas y apropiadas a partir de los cruces intertextuales con la prensa de la época. Recogemos registros de las primeras proyecciones y de sus antecedentes, caracterizando el modo en que fueron recibidas las primeras imágenes importadas desde Europa y Estados Unidos que impusieron un sistema industrializado y sirvieron de modelo a las cinematografías locales.

Palabras clave: cine temprano, precine, cinematógrafo.

Abstract - The arrival of cinema in Latin America and Chile in particular, can compose a map of early cinema in this side of the world. This article aims to advance the configuration of a picture of when they met film technologies available in the late nineteenth century, how they were named and appropriate from intertextual intersections with the press of the time. We collect records of the first projections and their history, characterizing the first images imported from Europe and the U.S. not only imposing an industrialized system but a way of building the image, which became the model for the local cinema.

Keywords: early cinema, pre-cinema, cinematograph. 
La llegada del cine a América Latina en general, y a Chile en particular, está vinculada a la modernidad en el contexto urbano. El cine marcó desde una nueva concepción del espacio y del tiempo hasta nuevas formas de mirar, la posibilidad de conocer tierras lejanas, duplicar la realidad, trascender a la muerte y reproducir el movimiento. Para que ello ocurriera fue necesario que se desarrollara la tecnología cinematográfica. Sus antecedentes están en numerosos aparatos que corresponden a lo que algunos teóricos han llamado pre-cines, cuyos dispositivos no tardaron en transitar desde Europa y Estados Unidos hacia este lado del mundo.

Uno de los aspectos que ha ocupado a los historiadores del cine es el tema de su origen, no existiendo una fecha determinada para ello, sino más bien, entendiéndolo como un proceso de tránsito y experimentaciones en torno a la imagen y el movimiento. Si bien se asume convencionalmente que el nacimiento del cine ocurrió con los hermanos Lumière en el Grand-Café de París, en el Boulevard des Capucines, el 28 de diciembre de 1895, hay un recorrido previo y otro que se extiende hasta 1908, cuando se impone el modelo narrativo hegemónico de Griffith.

Algunas perspectivas, como la de Arlindo Machado, apuntan hacia el hecho de que la historia de la invención técnica del cine no solo abarca investigaciones científicas de laboratorio o inversiones en el área industrial, sino que también es necesario considerar otro escenario donde caben distintos tipos de espectáculos de masa, como era habitual en el siglo xIx e incluso antes, como la fantasmagoría (proyecciones de fantasmas de Robertson, entre otros), prestidigitadores de ferias y kermeses, el teatro óptico, fabricantes de juguetes y adornos de mesas, médiums y charlatanes. La historia del cine ha privilegiado el punto de vista del positivismo técnico, las teorías científicas de la percepción y los aparatos asociados al movimiento, desconsiderando la voluntad milenaria de intervenir el imaginario (14).

Más allá de estos antecedentes, nos preguntamos aquí cómo fue exactamente el momento del debut cinematográfico en distintas zonas de Chile, tema poco explorado aún, avanzando sobre los datos existentes sobre las primeras proyecciones en agosto de 1896 en el Teatro Unión Central de la Santiago ${ }^{1}$, en el contexto latinoamericano.

Teatro de sombras (2009), de Carmen Luz Maturana, arroja luces sobre la etapa previa al cine en Chile, estudio que se suma a los textos que aportaron anteriormente al relato historiográfico del cine temprano en nuestro país, como El cine mudo (1994), de Eliana Jara, o Una breve mirada al cine mudo chileno (2010), de la misma autora, y Breve historia del cine chileno. Desde sus orígenes hasta nuestros días, de Jacqueline Mouesca y Carlos Orellana, entre otros. El libro 1900 (1999), de Alfonso Calderón, agrega elementos respecto a las primeras exhibiciones cinematográficas en el país, en el contexto de usos y costumbres de la época, así como La sociedad de los artistas (2007), donde Carlos Ossandón examina las nuevas figuras asociadas a las artes hacia fines del siglo XIX y principios del xx. El estallido de las formas (2005), de Carlos Ossandón y Eduardo Santa Cruz, explora en la naciente "cultura de masas» desde fines del xix hasta las primeras décadas del siglo $\mathrm{xx}$, momento en que surgen revistas magazinescas y especializadas, la fotografía impresa y el cine. Archivos i letrados (2011), de Wolfgang Bongers, María José Torrealba y Ximena Vergara, si bien se sitúa entre 1908 y 1940, también da cuenta, en un conjunto de crónicas de esa época, del impacto, legitimación, funciones y otros aspectos del cine de los primeros tiempos en Chile. Y el texto de Valeria de los Ríos, con Espectros de luz. Tecnologías visuales en la literatura latinoamericana (2011), contribuye a establecer el contacto entre el cine y la literatura en el periodo que nos interesa. Autores como Tom Gunning (2004,1995a, 1995b), Leo Charney y Vanessa Schartz (2010), Arlindo 
Para ello, indagamos en el diálogo intertextual en la prensa de la época, focalizando el momento de la llegada del cinematógrafo en las ciudades de Iquique, Concepción, Valdivia, Punta Arenas, Valparaíso y Santiago.

\section{ALGUNOS ANTECEDENTES}

Es posible advertir coincidencias en lo que autores como Sadoul (1949), Deslandes (1966) y Mannoni (1995) apuntan como antecedentes de la invención técnica del cine: la creación de los teatros de luz por Giovanni della Porta (siglo xvi), las proyecciones criptológicas de Athanasius Kircher (siglo XVII), la linterna mágica de Christiaan Huygens, Johannes Zahn, Samuel Rhanaeus, Petrus van Musschenbroek y Edme-Giles Guyot (siglos XVII y XVIII), el panorama del artista escocés Robert Barker (siglo XVIII) y, luego, en el siglo XIX, la fotografía de Nicéphore Nièpce y Louis Daguerre, los experimentos de Joseph Plateau con la persistencia retiniana y los ejercicios de descomposición del movimiento del fisiólogo Étienne-Jules Marey y Eadweard Muybridge, hasta llegar a los descubrimientos e invenciones que reunían, en un único aparato, muchos de los hallazgos señalados: los inventos de Thomas Edison, Louis e Auguste Lumière, Max Skladanowsky, Robert W. Paul, Louis Agustin Le Prince y Jean Acme LeRoy (Machado 12).

Agregamos a ello, más allá del logro de la síntesis del proyector, que el inglés Muybridge registró el movimiento de caballos con placas de coloidón húmedo, hacia 1872 . Por otra parte, hay referencia, ya en 1851, de las primeras fotografías animadas desarrolladas en el taller de Nièpce, mientras que Marey, creador del cronofotógrafo de placa móvil, presentó en 1888 ante la Academia de Ciencias las primeras tomas de vistas en películas.

Si bien es reconocible el vínculo de varios de los mencionados con la ciencia (Marey, Londe y Muybridge), en contrapunto aparecen ilusionistas como Reynaud (creador del dibujo animado que proyectaba en su teatro óptico) y Méliès, personas clave en los primeros momentos del cine. No obstante, quienes lograron la síntesis de los inventos precedentes tenían un interés comercial en el nuevo invento, disputándose incluso territorios para explotar el sistema que incorporaba la técnica de proyección para numerosos espectadores, como ocurrió en Estados Unidos, por ejemplo.

Edison y Lumière querían crear un espectáculo interpelando al sujeto a través de dos modalidades coexistentes como antítesis: el realismo absoluto de los Lumière y el irrealismo de Méliès. La primera modalidad sorprendía al espectador con la simple posibilidad de «duplicación» del mundo visible que otorgaba la máquina; la segunda provocaba el deslumbramiento con la evasión hacia lo onírico y desconocido (Machado 18). Esta antítesis es ampliamente desarrollada por autores como Sadoul,

Machado (2008) y Flávia Cesarino Costa (2005), proporcionan nuevas perspectivas para observar el cine temprano, sumándose a clásicos como Georges Sadoul (1949), Nöel Burch (1999), entre otros. 
dado que establecerá la diferencia primigenia entre el documental y la ficción, aunque, aún en esos tiempos, no se definieran plenamente ambos campos.

Desde otro ángulo, las diversas tecnologías desarrolladas, desde el diorama de Daguerre a la kinetofotografía de Edison, si bien son vistos como pasos conducentes al cine, fueron también pasos hacia la «recreación de la realidad». Se constituyeron entonces ciertas estrategias de restitución de lo real, con la sensación de relieve y movimiento. Los planteamientos estéticos de Panofsky y el vínculo entre las prácticas artísticas y científicas, en el uso de la perspectiva, así como el fenómeno de la persistencia retiniana como medio mnemotécnico en la enseñanza, será de gran interés para los primeros inventos precedentes al cine, así como también el desarrollo de la técnica para la reproducción del movimiento (Burch 25).

Burch destaca la presencia de Edison y su voluntad de reproducir imágenes y sonido, en un afán no solo industrial sino de verdadera "conquista de la naturaleza» y de triunfo de la vida sobre la muerte. Esta idea de triunfo de la vida sobre la muerte será advertida también por Edgar Morin (2001), quien enfatiza la difusión del cinematógrafo como un fenómeno de magia y apunta el mito último y primero de la cinematografía: el cine total, la inmortalidad.

Si bien se define al cine como una actividad colectiva de recepción de filmes, no deben desconsiderarse las formas individualizadas de exhibición que no contemplaban proyección, como el kinetoscopio y el mutoscopio, según apunta Flávia Cesarino Costa. El primero, inventado por Edison, apareció en 1894 en los Estados Unidos y consistía en la exhibición de filmes dentro de una especie de caja con un visor individual que funcionaba con una moneda.

La muerte de María Estuardo y The Kiss, un filme de erotismo ingenuo, figuran entre los éxitos para el espectador privado. Danzas del vientre, bailarinas, escenas eróticas y mujeres en ropa interior, animales amaestrados, entre otros, eran el repertorio de películas perforadas de 50 pies, mientras la cámara que realizaba estos filmes se denominó kinetógrafo. El mutoscopio, inventado por Dickson en 1895, fue otro aparato que mostraba imágenes fotográficas a través de un visor, solo que su base era el papel y no el filme. Dickson salió de la compañía Edison y formó la American Mutoscope Company, que luego desarrolló el proyector Biograph, convirtiéndose en la competencia de Edison, con la American Mutoscope and Biograph Company, que adquirirá relevancia posteriormente.

Pero fue la llegada del cinematógrafo Lumière a Estados Unidos, en enero de 1896, lo que generó la fabricación de otra tecnología: el vitascopio. No obstante, el sistema Lumière logró instalarse en la red de vaudevilles y los teatros de variedades, por lo que la estrategia de venta de Edison no había funcionado. Hacia 1897, este perfeccionó su sistema, instalando el Projecting Kinetoscope, al mismo tiempo que consiguió expulsar a los Lumière del mercado estadounidense. Con todo, el cine de la primera década fue controlado por los operadores / exhibidores (Cesarino Costa 44). 
Musser discute ampliamente la producción de Edison en relación a la de los hermanos Lumière. Edison, Dickson y otros empleados del laboratorio Edison frecuentaron las estrellas de variedades y las peleas de box, estableciendo una relación entre el juego, la diversión y la creatividad para realizar sus películas, orientándose, en la fase del kinetoscopio, al voyeurismo masculino. El laboratorio, en sus primeros tiempos, era un bastión de la cultura masculina. No sorprendía, por ello, que los kinetoscopios exhibieran peleas en bares o imágenes de la sensual bailarina española de music hall, Carmencita. Asimismo, realizaron numerosas filmaciones de performance de mujeres con componentes eróticos: y «estos filmes de sexo y violencia tenían un fuerte sentido comercial, pero los realizadores tendían a imaginarse una audiencia de hombres como ellos mismos»(22). Por este motivo, Musser califica los filmes de Edison como «homosociales», mientras que los de Lumière corresponderían a películas «heterosociales», enfatizando la esfera doméstica en sus principios, para luego expandirse a la esfera pública, llegando a constituir sus más relevantes filmes a partir de imágenes de la familia, la nación y el Estado, todos ellos ignorados en las imágenes de Edison en el periodo del kinetoscopio. Más tarde, en la etapa del vitascopio, Edison y su equipo filmaron en locaciones exteriores de Nueva York, Brooklyn, Coney Islad y las cataratas del Niágara. Pero la diferencia estaba en que mientras el primero presentaba vistas norteamericanas, el segundo exhibía vistas internacionales europeas, no solo francesas, sino italianas, suizas y rusas, entre otras.

Por otra parte, hacia 1896, las bases de la industria cinematográfica ya estaban sentadas a nivel mundial. En Francia, Lumière, Méliès, Pathé y Gaumont cubrían el mercado; en Londres, William Paul y; en Estados Unidos, Edison y la Biograph lograron consolidarse.

Las nuevas tecnologías, con diversos nombres, aparecerán en las primeras proyecciones realizadas en América Latina, sin embargo, es difícil identificar los aparatos porque eran adaptados en los espacios locales siendo nombrados de diversos modos. La presencia de la tecnología de Edison y la de los Lumière también será ampliamente comentada por los cronistas de la época. En Chile aparece mencionado el cinematógrafo Lumière, el cinematógrafo parisiense, el «biógrafo americano», el kinetoscopio y el vitascopio, aunque también hay alusiones al cronofotógrafo, al estereopticón y el fonocinematógrafo, entre otros.

\section{PRIMERAS PROYECCIONES, ACTUALIDADES Y CINE DE ATRACCIONES}

En sus primeros tiempos, el cine estuvo fundamentalmente destinado al espectáculo, aunque también han sido reconocidas sus utilizaciones con fines científicos y educativos. Junto con presentar un esquema de exhibición como espectáculo, constituía también una forma de representación que Burch ha denominado "cine primitivo". El autor acota que utiliza el concepto «primitivo» en el sentido de "primero», «original», pero también en el de «frustrado», "grosero», según «todas las normas 
que se han vuelto las nuestras (incluyendo a todas las clases sociales) en los países industrializados» (16).

Su tesis es que el periodo que transcurre entre 1895 y 1929 es el momento de constitución de un «Modo de Representación Institucional» (MRI) que se enseña como lenguaje del cine, con lo que se adquiere una competencia de lectura de las películas en las sociedades industriales, por lo que, previo a esta idea, se trataba del Modo de Representación Primitivo, cuyas características apuntan a la autonomía del cuadro (incluso después de la introducción del sintagma de sucesión), posición horizontal y frontal de la cámara, conservación del cuadro de conjunto y centrífugo. La presencia de un eventual comentarista en la sala y de los textos, sumado a lo anterior, define la «exterioridad primitiva» (194).

Otro aspecto que caracteriza este modo de representación primitivo es la noclausura, aspecto que se refiere a las múltiples interpretaciones del relato de lo que podrían considerarse primeras ficciones, dada la subjetividad del comentarista, las grandes elipsis de las historias narradas y el marco de la proyección. Las películas de los primeros tiempos, entre 1900 y 1908, pasado el momento de los filmes de una sola toma o de un solo plano, pueden ser caracterizadas por la no continuidad.

La perspectiva de Burch puede ser cuestionada. Otras nomenclaturas nos parecen más pertinentes. Cesarino Costa utiliza el término primeiro cinema para designar a los filmes y prácticas asociados a estos durante el periodo comprendido entre 1894 y 1908, aproximadamente. Propone esta denominación en portugués a partir de la denominación inglesa early cinema, que aquí traducimos como cine temprano. También se refiere al cine de los primeros tiempos (cinéma des prémiers temps), expresión acuñada por el francés André Gaudreault (cit. en Cesarino Costa 34). El problema de este concepto, según la autora, es que fue concebido para construir una teoría de los procesos narrativos del cine sin considerar el aspecto histórico, más allá de la semiótica. Concordamos con esta discusión en torno a la no utilización de los términos cine primitivo o filmes primitivos, acuñados por Nöel Burch, aunque lo utilicemos para explicar la caracterización de este autor para el cine temprano. La idea de "primitivo» tiene connotaciones negativas al compararse con la narrativa tradicional hegemónica impuesta a partir de 1908 por Griffith, siendo considerado como poco evolucionado.

Más allá de la técnica, en relación a los primeros filmes proyectados, los programas anunciados a este lado del mundo concordaban con las imágenes que se difundieron en Europa y Estados Unidos. El límite entre la ficción y el documental -considerando genéricamente el término- era poco nítido. En general, a nivel mundial, las actualidades predominaron hasta 1903 y se tornaron muy populares a causa de las guerras imperialistas que involucraban a Europa y a Estados Unidos. Vida cotidiana, escenarios naturales, paisajes de tierras distantes, multitudes en las calles, eran comunes en este tipo de cine. Los filmes Lumière son un claro ejemplo de ello. Sus camarógrafos registraban vistas familiares de sus cercanos y solían salir 
a la calle para filmar escenas cotidianas, aunque muchas veces fingían accionar la manivela de la cámara con el fin único que las personas (aparentemente filmadas) fueran a las funciones. Sin embargo, también fueron habituales las «actualidades reconstituidas», es decir, escenificaciones que pudiesen interesar a los espectadores.

En ese contexto fue frecuente la modalidad del desarrollo de conferencias de viajeros ilustradas con sus películas. El género internacional de filmes de viajes, denominado travelogue, cuyo origen se remonta a la tradición y práctica de la linterna mágica, será relevante a la hora de reproducir en el viejo continente la imagen de Latinoamérica desde una perspectiva eurocentrista. La linterna mágica, «invención óptica del siglo XVIII en Europa, mezcla de instrumento científico y máquina de ilusión y fantasmagoría, que se mantuvo durante tres siglos reproduciendo imágenes artificiales, fijas y animadas para un público interesado en diabluras, escenas grotescas, eróticas, religiosas, históricas, políticas y satíricas» (Mannoni cit en Schvarzman 48)², convivió incluso con el cinematógrafo en América Latina, como registra la prensa.

Por otra parte, el cine temprano, antes de 1908, corresponde predominantemente al "cine de atracciones", que luego fue redefinido hacia nuevas formas narrativas en función de fuerzas económicas y sociales que tuvieron que ver con el desarrollo de la industria cinematográfica y la enorme expansión de la exhibición de los nickleodeons, en el caso de Estados Unidos.

Las imágenes muchas veces estaban basadas en la estética del asombro, apelando a la curiosidad de los espectadores con respecto a las nuevas tecnologías, más allá de los contextos de exhibición instalados en ferias, parques de diversiones, circos, teatros o los primeros salones. Tom Gunning define el «cine de atracciones», diseñado a partir de breves momentos de imágenes en movimiento, como un cine de sorpresas, con vistas simuladas, en algunos casos. Este cine apelaba directamente al espectador, generando un campo de expectación y suspenso y no necesariamente estaba restringido a una sola toma. Las transformaciones de los filmes de Méliès otorgan el modelo más obvio de un filme de atracciones, con una sucesión de apariencias mágicas, transformaciones y desapariciones. Advierte el autor que, si bien no todo el cine de atracciones estaba pensado para provocar un shock en el espectador, no necesariamente generó el pánico que lo identificaba con un realismo extremo, como han sugerido algunos teóricos. No obstante, según esta perspectiva, este cine de atracciones «[...] verdaderamente invoca la temporalidad de la sorpresa, shock, y trauma, la repentina ruptura de la estabilidad producida por la transformación [...]» (Tom Gunning, «Now you see it...» 49).

Sheila Schvarzman desarrolla ampliamente este tema en "Travelogue e cavação no Brasil pitoresco de Cornélio Pires» (2011). 


\section{EL CONTEXTO LATINOAMERICANO}

Desde su llegada al continente hasta las primeras tres décadas del siglo xx, es posible distinguir aspectos comunes en el cine que se proyectaba en Latinoamérica: el interés por exhibir filmes realizados tanto en lugares lejanos (principalmente Europa) como cercanos (las producciones locales), la alianza del cine con los jardines de recreo (parques de atracciones de principios de siglo), los teatros y otros espectáculos públicos, y el cine como medio de expresión de noticias sensacionales y obras literarias. Más tarde vendrían, a partir de la década de 1910, los filmes de argumento, muchos de ellos inspirados en hechos o personajes históricos, fortaleciendo de ese modo el ideario nacionalista, como ocurriera en Chile con Manuel Rodríguez, protagonista del primer filme de argumento (1910).

Mención especial merecen algunas tecnologías previas, como el panorama y las linternas mágicas ya mencionadas, que tuvieron una presencia importante a este lado del mundo. El panorama, un enorme cuadro esférico en que el espectador se sitúa al centro y puede ver el horizonte como si estuviese en lo alto de un monte, tuvo exponentes relevantes en América Latina, como el brasileño Víctor Meireles, que, en dupla con el pintor belga Langerok, expuso con gran éxito en la Exposición Universal de París su Panorama da Cidade do Rio de Janeiro. Por otro lado, hay registro del uso de la linterna mágica hasta principios del siglo xx, incluso cuando se había expandido la tecnología cinematográfica, con una exhibición de «lindísimas vistas de linterna mágica» al interior del jardín zoológico de Río de Janeiro en 1905. Lo mismo ocurrió con el «fantascópio», de Robertson, que proyectaba fantasmagorías y de cuya presentación hay huellas hacia fines del siglo XIX (Araújo, A Bela época do cinema brasileiro 56).

Si pensamos en este contexto, la llegada del cine a fines del siglo xIX como un invento científico y una nueva tecnología importada, incluyendo «vistas» producidas en el extranjero, no generaban otra cosa que no fuese admiración y voluntad de reproducir, en el ámbito de lo nacional, aquello que llegaba desde afuera.

Las primeras proyecciones de las imágenes de los Lumière se realizaron en Brasil en julio de 1896. En Chile, la tecnología apareció en agosto de ese mismo año, casi al mismo tiempo que en Argentina, Uruguay y México. No obstante, López consigna

que hay evidencia que el British Brighton School films (usando el vivomatógrafo) tuvo una première en Buenos Aires el 6 de julio de 1896, lo que la autora explica por la estrecha relación neocolonial entre Inglaterra y Argentina durante este período (50).

La proyección con el sistema Lumière, realizada en la rua del Ouvidor 57 en Río de Janeiro, apareció con el complejo nombre de omniographo. La noticia, publicada por el Jornal do Comércio del 8 de julio de 1896, anuncia el invento "que tanta atracción tuvo en París» y, al día siguiente, el 9 de julio, ya comentando la inauguración de la noche anterior, lo compara con el kinetoscopio advirtiendo sus ventajas al ofrecer una visión no solo a un espectador, sino a centenas de personas. 
La crónica registra que estaban dispuestas unas doscientas sillas, que el telón medía dos metros, aproximadamente, y que el aparato se sitúa detrás de los espectadores, en un pequeño gabinete cerrado colocado entre las dos puertas de entrada. No hay referencia, no obstante, al nombre del empresario o exhibidor del espectáculo. Sí se advierte: "Tal vez por defecto en las fotografías que se suceden rápidamente, o por inexperiencia de quien trabaja con el aparato, algunas escenas se mueven indistintamente en vibraciones confusas; otras, sin embargo, resaltaban nítidas, firmes, acusándose en un relevo extraordinario, dando magnífica impresión de la vida real» (cit. en Araújo, A Bela época do cinema brasileiro 74-5).

Con la información existente, Araújo duda respecto a si se trataba más bien de un kinetógrafo perfeccionado y adaptado para la visión colectiva. Pese a ello, el omniographo fue el primer aparato que proyectó vistas animadas en la ciudad de Río de Janeiro. El tema de la denominación puede deberse a que se realizaban adaptaciones locales de los aparatos que llegaban desde el extranjero. El 14 de enero de 1897 hubo una presentación para la prensa en esa misma ciudad del kinetographo portuguez (sic), traído por Aurélio da Paz dos Reis desde Portugal. Citamos este ejemplo porque en Chile también aparecieron distintas denominaciones para el nuevo invento y sus variedades.

En México es posible seguir la huella de los camarógrafos Lumière y obtener, según su perspectiva, el registro de las primeras proyecciones del cinematógrafo, lo que permite vislumbrar cómo funcionaban estos operadores en el continente. Gabriel Veyre, representante de Lumière, relata en primera persona, en una serie de cartas a su madre, su experiencia en ese país. Veyre, quien había llegado a México junto a Claude Fernand Bon Bernard, concesionario para explotar el aparato en México, Venezuela, las Guayanas y las Antillas, instaló el sistema luego de sortear no pocas dificultades. La primera fue encontrar un lugar adecuado, para lo cual arrendó por dos meses el entresuelo de la droguería Plateros, de la Segunda Plateros 9, sede de la Bolsa de México. El segundo inconveniente fue la luz eléctrica necesaria para proyectar, tema que debió resolver el propio operador. Pero antes de la exhibición pública, de acuerdo al relato de Aurelio de los Reyes, el 6 de agosto de 1896 Veyre y Bon Bernard realizaron la primera función de cine en México para el general Porfirio Díaz, en su residencia del castillo de Chapultepec, a la que asistió también su esposa y unos cuarenta invitados (11). El 14 del mismo mes hubo otra función para prensa y grupos de científicos, pero los empresarios, por temor a que no asistiera público, invitaron a más de 1.500 personas que luego no sabían dónde instalar, según narró el operador en una carta a su madre fechada el 16 de agosto de 1896, en México. La primera función abierta al público, después de ese debut, "ha estado un poco deslucida por la lluvia», pero no hubo mala concurrencia. Los preparativos, luego de arrendar el local, no fueron pocos:

[...] Todo está listo, ¡menos la luz! Fuimos a la compañía de electricidad; no tenían el tipo de corriente que necesitamos. Y sin embargo necesitábamos funcionar porque corrían los gastos. Buscamos máquinas de vapor, máquinas eléctricas, nada servía. Regresé con el 
electricista donde probé todas sus lámparas. ¡Nada marchaba! Así permanecimos durante largos seis días, en la ansiedad, hasta que me vino la idea de combinar su lámpara con la mía. Probé y pude iluminar la pantalla. Todo marchó bien desde el punto de vista de las proyecciones; al final de la jornada eché un suspiro de satisfacción [...] (Veyre 42).

En esa misma misiva, Veyre se refiere a filmaciones que realizó con el Presidente de la República paseando en su parque, una maniobra en el Colegio Militar y bañistas haciendo saltos mortales: "Todas están bien logradas y las enviaré a Lyon» (43).

Pero, sin duda, en esta correspondencia también es posible identificar la mirada eurocéntrica con que los camarógrafos Lumière obtenían las vistas del continente, que luego eran enviadas a Europa o, en algunos casos, circulaban dentro de América Latina. La carta desde Guadalajara, del 6 de noviembre de 1896, es elocuente:

[...] La segunda vista es un indio montado sobre un toro sin silla. El toro salta y da cornadas a diestra y siniestra para tirar al jinete. Hacia el final de la vista, el toro da un brinco tal que cae con todo y jinete. Esta vista será muy bella y curiosa para los europeos. Creo regresaré a esa hacienda uno de estos días para tomar más vistas [...] (Veyre 46).

En el mismo documento, el operador da cuenta de la llegada de un segundo aparato que, en manos de Bon Bernard, iría a Monterrey, lo que les garantizaba una explotación más rápida. Veyre se dirigió luego con el cinematógrafo a La Habana, desde donde escribe en febrero de 1897. Luego intentó llegar a Venezuela, pero el barco en que viajaba es devuelto a Cuba por un caso de viruela a bordo. De Cuba partió hacia Colombia, desde donde se comunica con su madre el 14 de junio de 1897, comentándole que irá a Panamá para:

instalar mi aparato una quincena de días. Apenas instalado lo dejaré allá con el empleado para ir yo mismo a Barranquilla, a dos días de vapor de aquí. Allá estudiaré la ciudad desde el punto de vista de la explotación y trazaré mi itinerario. Es probable que después de Barranquilla vaya a la capital, Bogotá (55).

Llegó finalmente a Caracas, donde fue estafado por un comerciante, por lo que suspendió las funciones. Este relato permite vislumbrar el perfil de los operadores Lumière, quienes viajaban proyectando vistas europeas y filmando en escenarios locales con el objetivo de explotar comercialmente el invento. Además de describir las condiciones de proyección, es evidente su interés por hacer del cine un negocio rentable tanto a nivel de exhibición como de producción.

En relación a las imágenes proyectadas en un primer momento, estas corresponderían al cine de atracciones descrito por Gunning. Sin embargo, Valeria de los Ríos apunta que este cine de atracciones en América Latina se vio complicado por el estatus del cine como aparato, es decir, el asombro de los espectadores no solo se dirigía hacia la imagen proyectada, sino hacia la máquina en sí, apareciendo un cierto fetichismo identificable en las crónicas de la época. Al igual que en otros lugares del mundo, el cine llama la atención por su «efecto realidad», tema que constata en 
publicaciones del 20 de julio de 1896, dos días después del debut del cinematógrafo Lumière en el periódico argentino El Diario y en El Mundo, de México, en 1900. Pero, por otro lado, la autora también advierte que en las crónicas latinoamericanas se observan elementos asociados a lo mágico, lo fantasmagórico y lo espectral, como ocurre en escritos del mexicano José Juan Tablada.

Por otra parte, analizando crónicas de El Diario, en Argentina, De los Ríos enfatiza otros elementos, como el ímpetu nacionalista, hacia 1897, con la filmación de eventos locales. El cine como espectáculo masivo y homogeneizador también aparece en las crónicas latinoamericanas de la época, aunque se advierte una separación entre el público masivo y los intelectuales, como ocurre en una crónica del poeta y cronista mexicano Luis Gonzaga Urbina en 1906, "La vuelta del cinematógrafo», al señalar que los espectadores de cine son «el gentío pobre»(208-10).

\section{LA LLEGADA A CHILE}

El 26 de mayo de 1858, en el Salón de la Filarmónica del Teatro Municipal, el químico Manuel Meyer presentó en Santiago un espectáculo de linterna mágica, de acuerdo al relato que recoge Alfonso Calderón como antecedente al cine: «Desfilaban por la pantalla escenas bíblicas, campestres, selváticas, desérticas, cordilleranas. Marinas, panorámicas y humanas» (269).

Por otra parte, el kinetoscopio de Edison fue presentado por el empresario Francisco de Paola en una sala de la calle Estado 171, el 19 de febrero de 1895: «Una de las cintas mostraba un individuo que jugaba con un perro terranova; la segunda, unos herreros que, entre martillazos en el yunque, bebían sus buenos vasos de vino; otra, una reyerta animadísima en una fonda; la de más allá, una riña de gallos, y, la última, las danzas de una bailarina famosa» (270):

Es posible obtener una descripción técnica del aparato de Edison de acuerdo a El Ferrocarril, de febrero de 1895:

[...] En un segundo se obtienen 36 vistas diferentes y continuadas. Estampadas y acumuladas esas fotografías en una angosta faja de seloidina de unos 15 metros de largo, van presentándose a través de un cristal iluminado con luz eléctrica y al compás de las agujas de una esfera que giran con celeridad en una serie no interrumpida (cit. en Eliana Jara, El cine mudo chileno 15).

Se observa además una referencia explícita al funcionamiento del fonógrafo.

El cinematógrafo Lumière llegó a Chile en 1896. La exhibición ocurría en salones que rápidamente proliferaron en las ciudades de Santiago, Valparaíso e Iquique, pero las «vistas animadas» se desplazaron también a espacios como ferias o simplemente acompañando obras de teatro y, especialmente, zarzuelas itinerantes. Por un lado hay una escasa diferencia temporal entre la llegada del cinematógrafo a la capital (Santiago), el puerto principal (Valparaíso) y a la ciudad de Iquique, también enclave 
portuario y, por otro, no ocurrirá lo mismo con el extremo sur, en Punta Arenas o en ciudades intermedias como Concepción y Valdivia.

Es posible distinguir una etapa inicial de «nomadismo», pero luego el cine se transforma en una actividad sedentaria y regular con la instalación de la sala de biógrafo. No obstante, será hacia 1909 cuando el cine sale del centro de la ciudad de Santiago y se sitúa en las barracas, convirtiéndose en un fenómeno popular (Iturriaga 17).

El sistema francés de proyección convivió con el norteamericano. El vitascopio de Edison y el cinematógrafo Lumière llegaron importados por extranjeros. El cinematógrafo, con la tecnología importada de París, debutó el 25 de agosto de 1896 en el Teatro Unión Central de Santiago. Julio Prá Trilles, un francés radicado en Chile, dueño de la Casa Prá, una gran tienda de ropa, menaje y curiosidades, fue quien importó el aparato que se instaló en el céntrico teatro ubicado en calle Ahumada, donde se habilitó la primera sala de cine, en el Salón de Patinar, con capacidad para 150 personas y alumbrado con luz eléctrica. El vitascopio de Edison también es instalado en junio de 1897 en una nueva sala, «El paseo de los Campos Elíseos», inaugurada en diciembre en la calle Huérfanos con Miraflores. Pocos días antes, el Teatro Unión Central inauguró el vitascopio gigante, pero ambos tuvieron corta vida (Jara, El cine mudo chileno 18).

Tres eran entonces las salas que a inicios de siglo reunían a la aristocracia santiaguina en torno al cine: Apolo, Variedades y Kinora. El empresario Arturo Larraín Lecaros, quien luego formaría la Compañía Cinematográfica del Pacífico, fue el impulsor de esta última. Pero en 1903 el circo Quiroz Rodríguez cambió el perfil del espectáculo incorporando vistas del Biógrafo Americano, llegando así a sectores populares en su itinerancia por el país.

Las referencias a la primera exhibición cinematográfica en Chile están asociadas a los cuadros o vistas de los Lumière. La prensa de la época no registra exactamente los mismos títulos de los cuadros, dado que se habrían exhibido veinte vistas y algunas fueron comentadas y otras no, dependiendo del periódico y del cronista.

El programa de ese día 25 de agosto, según refiere el diario La libertad electoral, contemplaba: «Un mar ajitado, En una herrería, La llegada de un tren, El regador regado, Ejercicios de artilleros, La llegada de una familia, Alarma de incendio, Una calle en un día de lluvia, Un muelle y Desfile de coraceros» (cit. en Jara, "Una breve mirada al cine mudo...»176).

Por otra parte, el diario El Ferrocarril de Santiago del 26 de agosto de 1896, titula su crónica «Los cuadros animados del cinematógrafo» y se mencionan otras películas: En el comedor, Derrumbamiento de una muralla, Campamento de artillería, La papilla del bebé.

El texto describe ampliamente algunos de los «cuadros» proyectados, destacando «las escenas de más movimiento y vida», como el muelle de Marsella y «escenas de baños en que se ve saltar y correr el agua y el tiritar de los bañistas, el movimiento de una calle, un incendio, desfile de batallones, etc.». Destaca la alusión al movimiento 
y la reproducción de lo real, dos elementos que serán ampliamente comentados por la prensa de la época:

[...] La ilusión que produce el cinematógrafo es perfecta, es en realidad la prolongación de la vida. Solo falta la combinación del fonógrafo y de la fotografía de los colores para que la vida actual se perpetúe por medio del artificio de las ciencias físicas.

La concurrencia que asistió a este estreno del cinematógrafo aplaudió sin cesar esta maravillosa invención y felicitó cordialmente a sus introductores en el país, los señores Prá y $C^{a} »$ (El Ferrocarril, 26 de agosto de 1896).

La crónica del periódico santiaguino menciona el sentido último del cine, en tanto invención, y su cercanía con el avance científico y tecnológico en plena modernidad. También podemos asociar este discurso a lo que Burch y Morin plantean respecto al cine como posibilidad de trascender a la muerte.

Lo mismo sugiere el cronista del diario La Unión de Valparaíso del 9 de diciembre de 1896, cuando describe el ensayo del cinematógrafo instalado por la casa Prá y C $\mathrm{C}^{\mathrm{a}}$ (abreviatura usada para Cía.) ante la prensa y un centenar de espectadores en la calle Condell $\mathrm{N}^{\circ} 185$. La nota enfatiza la proyección de un cuadro «admirablemente realista» sobre un telón blanco. Destaca la presencia de señoritas y niñas entre el público.

\section{EL ESPECTÁCULO Y LA NUEVA TECNOLOGÍA ITINERANTE}

Otro aspecto asociado al cine de los primeros tiempos es la idea de espectáculo, hecho que advertía ya su cercanía con el music hall y el vaudeville:

«[...] La concurrencia gozó de veras con el novedoso y bonito espectáculo, riendo y aplaudiendo de buena gana al contemplar varios de los cuadros exhibidos. El único defecto que se notó pero que suponemos podría ser corregido es cierta trepidación en la imagen, que fatiga un tanto la vista [...]» (La Unión de Valparaíso, 9 de diciembre de 1896).

El último comentario alude al defecto técnico que es advertido a simple vista por el público en los sistemas de proyección de los primeros tiempos, como pudimos observar en el caso brasileño. Sin embargo, más allá de esa observación, encontramos varios enunciados que se refieren a la descripción y a las bondades de la nueva tecnología.

En Valparaíso, antes de la primera exhibición ya se anunciaba cómo operaba técnicamente el invento: «[...] Por medio de estas proyecciones, se reproduce la vida animada de una manera palpitante, siendo asombroso el número de vistas que pasan ante los ojos de los espectadores, pues entendemos que alcanzan, fíjense nuestros lectores, a novecientas por minuto" (La Unión de Valparaíso, 6 de diciembre de 1896).

En días sucesivos, las funciones del cinematógrafo, incluyendo el listado de vistas que se exhibirían, son anunciadas por el recién mencionado periódico como « ¡La más grande atracción del siglo!». El 23 de diciembre distinguimos una apelación 
al gusto del público: «Por la noche, en lugar de alguna de las vistas anteriores, se exhibirá, a pedido general, La llegada de un tren».

No hay registro de vistas locales exhibidas en Valparaíso en ese momento pese a que, como era común, se detallaba el programa de cada una de las funciones anunciadas. Por otra parte, al igual que en otros países del continente, el arribo de barcos con cargamentos de nuevas vistas europeas eran foco de noticias de fines del siglo XIX:

El cinematógrafo.

Ha recibido últimamente por el vapor Iberia un nuevo surtido de vistas que no dudamos interesarán á todo el mundo por ser tan de actualidad.

Nos referimos a las que representan á los soberanos rusos durante su coronamiento en Moscow, como también sus varias visitas en París acompañados del presidente de la república francesa, Sr. Félix Faure (La Unión de Valparaíso, 12 de enero de 1897)³.

Otra referencia permite apuntar que la itinerancia dentro y fuera del país fue habitual. El sistema Lumière incluía proyectores, filmes y operadores que actuaban como camarógrafos (también nombrados como cinegrafistas) y proyectoristas. La mayor ventaja sobre el vitascopio era la maniobrabilidad: el aparato era, al mismo tiempo, cámara y proyector, era liviano y funcionaba a manivela para filmar, sin necesidad de electricidad, aunque su uso como proyector requería del sistema eléctrico. El vitascopio, por el contrario, pesaba cerca de quinientos kilos. El cinematógrafo era fácil de transportar y podía llegar a lugares más apartados, incluyendo el mundo rural.

Cumplido un período de exhibiciones en Valparaíso, el cinematógrafo fue destinado al norte. El 6 de febrero de 1987 se anunciaba como el último día que se exhibiría en esa ciudad «este grandioso invento». Sus propietarios lo enviarían a Iquique, donde permanecería una corta temporada, para continuar su viaje rumbo a Bolivia.

En Iquique, ciudad ubicada en el extremo norte, se anuncia la llegada de «un gran cinematógrafo, que es el más perfecto de los aparatos de su clase, al decir de las revistas científicas que de él se han ocupado». Según la prensa de la época, su construcción es atribuida a M. Demeny, quien habría perfeccionado el cinematógrafo de Lumière, creando el "cronofotógrafo", que posibilitaba proyecciones de seis metros de largo por cinco de alto. La comparación con el sistema Lumière indicaba que ahora se podía proyectar en un gran teatro con el único requisito de contar con luz eléctrica. Junto con especificar que la proyección era ocho o diez veces mayor de la obtenida con el sistema Lumière, se enfatizaba la condición de espectáculo «realmente hermosísimo» y la proximidad con la vida real. La explicación de la técnica era simple para el lector, indicando que las escenas

«se obtienen por medio de miles de fotografías instantáneas, a razón de treinta ó cuarenta por segundo, y proyectadas por medio del aparato en un lienzo, producen en el ojo vibraciones que son a la vista lo que el fonógrafo es al oído, es decir, la im-

\footnotetext{
Conservamos la ortografía y puntuación original de la nota, incluyendo la preposición a con tilde.
} 
presión exacta de los movimientos de la naturaleza» (El Nacional de Iquique, 4 de Marzo de 1897).

Observamos que, junto con la valoración de la técnica, se reitera aquí la idea de reproducción de lo real, la duplicación del mundo visible que ofrecían las vistas Lumière. Llama la atención el uso del término cronofotógrafo y la alusión a Demeny.

Por la fecha, estimamos que se trataba del mismo aparato proveniente de Valparaíso, agregándose una referencia a que se trataría del único en su tipo existente en el país. El responsable de su arribo a Iquique fue Hermann Frank. «Esta noche se estrena en el Salón Filarmónico el cinematógrafo Lumière, único de su clase que por ahora hay en Chile. El precio de entrada será un peso» (El Nacional de Iquique, 10 de marzo de 1897).

El programa anunciado incluía dieciséis vistas Lumière estructuradas en dos tandas. En relación a las audiencias, aquella que asistió al Salón Filarmónico del Teatro Municipal correspondía a la elite local, según el relato del cronista: «Anoche asistió numerosa y selecta concurrencia, hallándose reunidas la mayor parte de las familias de Iquique» (El Nacional de Iquique, 13 de marzo de 1897).

Durante el mismo mes de marzo de 1897, se anuncia la llegada al puerto de Iquique de otro cinematógrafo, también perfeccionado. El aparato, que viajó a bordo del vapor Maipú, fue traído por M. Bautista y R. Klehmet. En este caso, hay una referencia al paso previo de ese equipamiento por los grandes teatros del Brasil, Uruguay y Argentina y de su retorno a Brasil "antes que cierre la cordillera", lo que confirma la circulación de tecnologías cinematográficas en América Latina. La proyección se realizó en los altos del Almacén Capella Hnos., ubicado en la plaza Arturo Prat.

Otro punto que llama la atención es el anuncio de la proyección de vistas en un cinematógrafo combinado con estereopticón. Al detallar los títulos de las vistas, se agrega al final el artefacto correspondiente. La proyección se realizó en El Dorado, un teatro-circo, con ocho vistas del primero y veintiuna del segundo (El Nacional de Iquique, 23 de marzo de 1897).

La descripción del evento, al día siguiente, evalúa ambos sistemas: «la impresión que ellas dejaron fue favorable en cuanto al estereopticón y poco satisfactoria con relación al cinematógrafo, por la trepidación y falta de luz en las vistas» (El Nacional de Iquique, 24 de marzo de 1897).

Las crónicas posteriores aluden a la baja de público, tema que explica, en parte, por la presencia del circo Quiroz en la ciudad. Otra referencia que nos parece relevante es aquella que menciona que el empresario del cinematógrafo que funcionaba en El Dorado se fue de gira a las salitreras. Este elemento sintoniza con la idea de la itinerancia del cine en los primeros tiempos, hecho que era favorecido por el contexto histórico de explotación del salitre en el norte de Chile, que significó los asentamientos en diversas oficinas cuyos obreros vivían en enclaves aislados en el desierto, lejos de los centros urbanos. 
Otro elemento significativo, además de la exhibición, es la producción cinematográfica local. Las primeras filmaciones nacionales se realizaron en la ciudad de Iquique. Su responsable fue Luis Oddó, quien provenía de la fotografía. Las vistas de interés local fueron anunciadas en Iquique el 15 de mayo de 1897 (Jara, Una breve mirada... 187). Sin embargo, como los títulos eran detallados no se advierte la presencia de proyecciones de películas nacionales sino hasta el día 26 de mayo, fecha en que se exhibiría Una cueca en la playa, Llegada de un tren de pasajeros y El desfile en honor del Brasil (El Nacional de Iquique, 26 de mayo de 1897).

Posteriormente, el día 30, se anuncia: «(Cuadro nacional) Una cueca en Cavancha», repetida en las dos tandas de la noche en el Salón de la Filarmónica.

\section{EDISON-LUMIÈRE: SISTEMAS PARALELOS}

En la ciudad de Concepción, las primeras noticias sobre proyección cinematográfica aluden al sistema inventado por Edison, que aparece registrado como el «fonocinematógrafo», en marzo de 1987. El periódico abunda en elogios:

El fono-cinematógrafo

Tuvimos el placer de asistir anoche al primer ensayo hecho en esta ciudad de este portentoso invento debido al fecundo jenio de Edison.

El esperimento no dejó nada que desear, siendo todas las vistas i piezas exhibidas de la unánime aceptación i aplauso de las personas invitadas, llamando especialmente la atención la escena de pujilato entre dos amigos i un incendio en Nueva York (El Sur de Concepción, 4 de marzo de 1897).

La noticia cita a "señores Celery i $\mathrm{C}^{\mathrm{a}}$ » como los empresarios a quienes se asocia la llegada de esta tecnología, al mismo tiempo que se refiere a «una de las creaciones más grandes del presente siglo» o al «acontecimiento del siglo». La descripción del espectáculo señala la exhibición de tandas divididas en seis cuadros cada una. El lugar donde funcionó fue el Salón de Patinar y el precio de las entradas era de \$1, «entrada jeneral» (sic), y \$ 0,50, niños, coincidiendo con los valores establecidos en otras ciudades del país.

La denominación de fonocinematógrafo complejiza la identificación del invento, pero estimamos que corresponde al vitascopio. Con una diferencia de poco más de un año, aparecen en Concepción las referencias al cinematógrafo Lumière, denominado aquí como "cinematógrafo parisiense», sistema que D’Ewefel Perol habría traído hasta esa ciudad para ofrecer solo algunas funciones en «el elegante teatrito del Skating Rink». De acuerdo a lo que registra la prensa:

El cinematógrafo parisiense dispone de ochenta vistas diversas i de alta novedad. Exhibe cuadros soberbios del último carnaval de Venecia, de la gran visita del Czar de Rusia a Francia, contando sobre este último suceso un buen número de cuadros de una exactitud sorprendente. 
El nuevo cinematógrafo dispone de cuadros de colores, no iluminados, como otros que conocemos, lo que contribuye a hacer mas palpables los sucesos que hace desfilar por el telon ${ }^{4}$ (El Sur de Concepción, 31 de mayo de 1898).

El cronista distingue las diferencias con las proyecciones antes realizadas en la región, enfatizando el color. Esta observación probablemente alude al sistema de teñido utilizado en esa época, distinto del iluminado manual. Nuevamente es destacada la relación entre el cine y lo real, pero, esta vez, agregado al elemento del color. Su presencia se anuncia también en otro lugar, el teatro de «El Trianon», como:

EL VERDADERO Cinematógrafo PARISIENSE SISTEMA LUMIERE llegado recientemente de París. 80 VISTAS DISTINTAS. Importantes acontecimientos europeos de actualidad.

Esta moderna i verdadera linterna májica no solamente es una diversión para los niños, sino también para toda clase de personas, puesto que la ciencia moderna, por medio de la fotografía, ha podido llegar a sorprender una sucesión de escenas de la vida real, que los aparatos reproducen con tal color de verdad, que dejan en el ánimo de todo espectador la impresión que produce la realidad (El Sur de Concepción, 2 de junio de 1898).

La alusión a la linterna mágica y a la fotografía permite establecer la idea de un proceso evolutivo en los dispositivos tecnológicos vinculados a la imagen en movimiento, según estimaban los cronistas de la época, enfatizando nuevamente la mirada positivista. Un aviso en el mismo periódico da cuenta de cómo convivieron ambos sistemas de proyección:

Cinematógrafo.

COMPLETAMENTE INSTALADO

FUNCIONA DIARIAMENTE

alternando con el kinetógrafo de 81/2 A 11 DE LA NOCHE

VISTAS EN COLORES DE MOVIMIENTO.

Por tandas de 6 vistas, renovándose en cada tanda tres vistas nuevas.

Entrada 50 centavos (El Sur de Concepción, 4 de junio de 1898)

Aparece aquí una nueva denominación para el sistema de Edison: el kinetógrafo, complejizando la configuración del campo de la exhibición en los primeros tiempos. Por otra parte, también en Concepción es posible distinguir la itinerancia del cinematógrafo, cuyas proyecciones, en junio de 1898, fueron anunciadas en la localidad de Lota (local de la Escuela de Hombres).

A modo de exploración, indagando por esta presencia en otras ciudades del sur del país, en Valdivia encontramos, en enero de 1897, una referencia a la llegada del fonógrafo, como último invento de Edison, casi al mismo tiempo en que ciudades

4 Conservamos la ortografía de la publicación original. 
como Concepción e Iquique exhibían los adelantos de la imagen en movimiento, lo que da cuenta del retraso de la llegada de las nuevas tecnologías a esta zona.

Recién en noviembre de 1900 hay registro en Valdivia del cinematógrafo en el teatro del Club Alemán Unión entre los días 14 y 16 de ese mes, anunciando la última función que sería "dedicada a niños de ambos sexos», agregando que, a petición de las familias, habría una función adicional el día 18. Lo anterior indica que el invento tuvo un breve paso por esta ciudad y que uno de los públicos escogidos para disfrutar el espectáculo fue el infantil.

En el extremo sur, Punta Arenas, aparecen indicios del cinematógrafo a inicios de 1899 en una publicación con formato de cuento aparecida en El Magallanes, que relata una función de cine en Madrid. La presencia del aparato en la región más austral de Chile se encuentra recién en 1900, con el anuncio de una función en el Club Alemán. La nota destaca la modernidad y asume una perspectiva positivista en la valoración del invento: «Se nos asegura que es uno de los de fabricación más moderna, reuniendo por consiguiente los últimos adelantos alcanzados por la ciencia» (El Magallanes, 14 de septiembre de 1900).

\section{LAS TANDAS}

La estructura en tandas reafirma la diversidad de las vistas, atribuible a la cercanía del cine de los primeros tiempos con el music hall y el vaudeville, como ya mencionamos, los espectáculos de linterna mágica, el circo y el teatro popular, más que con la novela del siglo xIx o el teatro clásico.

El cine temprano estuvo representado en las primeras imágenes que se exhibieron en Chile, utilizando tanto la tecnología francesa como la norteamericana. La enumeración de las distintas vistas, organizadas en tandas, da cuenta del amplio abanico de las imágenes Lumière que aparecen en las primeras proyecciones realizadas en distintas ciudades.

La Unión de Valparaíso del 15 de diciembre de 1896 anuncia las siguientes vistas: "1. ${ }^{\circ}$ Bomberos en Londres, $2 .^{\circ}$ Lanceros de la reina de España, 3. ${ }^{\circ}$ Marcha militar del batallón número 96 de línea español, 4. ${ }^{\circ}$ Un desembarco, 5. Ciclistas y jinetes en Londres, 6. Artillería española, 7. ${ }^{\circ}$ Un paseo en el parque de Londres, 8. ${ }^{\circ}$ Un baño de negros».

En los días sucesivos se enumeran nuevas imágenes, siempre referidas a escenarios europeos, incluyendo vistas en Londres, Alemania, Ginebra, Marsella, Budapest, Lyon, Niza, entre otros lugares.

El Nacional de Iquique del 10 de marzo de 1897, por ejemplo, detallaba el programa de vistas: 
EN UNA TANDA

1. ${ }^{\circ}$ El Czar y la Czarina entrando á la iglesia de la Asunción.

2. ${ }^{\circ}$ Delegación de asiáticos.

3. ${ }^{\circ}$ El Czar y su escolta en los Campos Elíseos.

4. ${ }^{\circ}$ Puente de la Concordia.

$5 .^{\circ}$ Escolta de cazadores á caballos.

6. Jefes asiáticos.

7. Batallón de «Turcos».

8..$^{\circ}$ Llegada del Czar á Cherbourg.

EN LA OTRA TANDA

1. ${ }^{\circ}$ Baño de negros.

2. ${ }^{\circ}$ Dragones atravesando un rio á nado.

3. Jugadores de naipes rociados.

4. ${ }^{\circ}$ Esgrima. El saludo.

5. Maniobras de caballería.

6. Salida de los talleres de la casa Lumière.

7. ${ }^{\circ}$ Llegada de un tren.

8. Inundación del río La Saône.

La exhibición empezará á las 8 en punto.

Algo similar ocurría cuando se anunciaban las vistas que se exhibían con la tecnología de Edison. Las publicaciones detallaban el programa de cada una de las imágenes y los comentarios se referían especialmente a algunas en particular, como «la famosa catarata del Niágara», destacada por El Sur de Concepción en 1897.

\section{ÚLTIMAS VISTAS}

Si bien este panorama nos ha permitido trazar un mapa de las primeras proyecciones de cine a lo largo de Chile en sus principales centros urbanos, podemos levantar algunas ideas conclusivas que no son del todo definitivas, dado que aún queda mucho por indagar al respecto, considerando que el cine silente es un objeto de estudio escasamente abordado en este país, en comparación con otros territorios del continente.

Nuevas hipótesis de trabajo, como el tema del tránsito de los camarógrafos / operadores por el territorio nacional y continental pueden ser propuestas; marcamos la existencia de aparatos de proyección provenientes de Europa y Estados Unidos y la aparición de modelos adaptados que también funcionaron en Chile, como en otros países.

Aunque en esta oportunidad no ahondamos en el contenido de las primeras imágenes proyectadas, sí advertimos que fueron las mismas que pudieron ver los espectadores europeos y norteamericanos. Destacamos en ese contexto que, si bien respondían a la estética del asombro, lo que más fue observado en la prensa de la época fue la técnica de proyección y, al mismo tiempo, la admiración por los avances de la ciencia, en clara sintonía con la admiración por los procesos de moderniza- 
ción representados fundamentalmente por la cultura europea, en primer término, y norteamericana, en segundo lugar. La respuesta del público, que obtenemos a partir de las crónicas de la época, se resume en algunos de los aspectos apuntados por Machado, Burch y Morin: el cine es visto desde una perspectiva positivista, como un nuevo invento de la ciencia, es también entendido como una tecnología que permite trascender a la muerte, se distingue su vocación de «duplicación» de lo real y también se observa su condición de objeto "mágico», aunque de este último aspecto no hay muchos antecedentes debido a que, al centrarnos en las publicaciones de las primeras proyecciones, nos instalamos en la modalidad de registro Lumière, sin abrir la posibilidad a la exhibición del material proveniente de Méliès, tema que también podrá ser desarrollado más adelante, aunque habitualmente la prensa de la época asocia al cine a los espectáculos de linterna mágica.

Podemos también proyectar la idea de la imagen del asombro, desde que las vistas que eran descritas, en muchos casos comentadas en detalle como ocurrió con el programa Lumière que se presentó en diversas ciudades, significaban, por un lado, la presencia de un cierto colonialismo visual y económico, considerando cómo operaron los sistemas de distribución desde Europa y Estados Unidos hacia Latinoamérica, tema que queda explícito también en muchas crónicas de la época y sobre el cual es posible seguir indagando.

A partir del testimonio de uno de los operadores Lumière en México y de la numerosa publicidad con que las funciones eran anunciadas, es visible que el cine temprano fue instalado, más allá de la perspectiva de un nuevo invento, como un negocio rentable tanto desde el punto de vista de la distribución como de la exhibición. El tema de la producción de vistas locales realizadas por extranjeros también significó, en un primer momento, la construcción de un imaginario sobre América.

\section{REFERENCIAS}

Araújo, Vicente de Paula. A Bela época do cinema brasileiro. São Paulo: Perspectiva, 1985. Medio impreso.

---. Salões, circos e cinemas de São Paulo. São Paulo: Perspectiva, 1981. Medio impreso. Bongers, Wolfgang, María José Torrealba y Ximena Vergara, eds. Archivos i letrados. Escritos sobre cine en Chile: 1908-1940. Santiago: Cuarto Propio, 2011. Medio impreso.

---. «El cine y su llegada a Chile: conceptos y discursos». Taller de Letras 46 (2010). Medio impreso.

Burch, Noel. El tragaluz del infinito. Madrid: Cátedra, 1999. Medio impreso.

Calderón, Alfonso. 1900. Santiago: Pehuén, 1999. Medio impreso.

Cesarino Costa, Flávia. O primeiro cinema: espetáculo, narração, domesticação. Río de Janeiro: Azougue, 2005. Medio impreso. 
Charney, Leo y Vanessa Schwartz, orgs. O cinema e a invenção de vida moderna. São Paulo: Cosac Naify, 2010. Medio impreso.

De los Reyes, Aurelio. «Gabriel Veyre en México. Comité para la conmemoración de los cien años del cine mexicano». Gabriel Veyre, representante de Lumière. Cartas a su madre. México: Filmoteca de la UNAM, 1996.

De los Ríos, Valeria. Espectros de luz. Tecnologías visuales en la literatura latinoamericana. Santiago: Cuarto Propio, 2011. Medio impreso.

Gunning, Tom. "'Now you see it, now you don't'. The temporality of the cinema of attractions». The Silent Cinema Reader. Eds. Lee Grieveson and Peter Kramer. London and New York: Routledge, 2004. 40-50. Medio impreso.

---. «racing the Individual Body: Photography, Detectives and Early Cinema». Cinema and the invention of Modern Life. Eds. Leo Charney y Vanesa Schwartz. Berkeley: Californa UP, 1995.

---. «An Aesthetic of astonishment: Early Film and the (In) Credulous Spectator». Viewing Positions. Ways of Seeing Film. Ed. Linda Williams. New Jersey: Rutgers University Press, 1995b. 114-33. Medio impreso.

Jara, Eliana. «Una breve mirada al cine mudo chileno con sus aciertos y descréditos». Taller de Letras 46 (2010). 175-91. Medio impreso.

---. El cine mudo chileno. Santiago: Imprenta Los Héroes, 1994. Medio impreso.

Kossoy, Boris. "La fotografía en Latinoamérica en el siglo xx: la experiencia europea y la experiencia exótica». Image and Memory, Fotography from Latin America 1866-1944. Ed. Wendy Watriss y Lois Parkinson. Texas: University of Texas Press-Fotofest, 1992. Medio impreso.

Lagny, Michele. Cine e historia: problemas y métodos en la investigación cinematográfica. Barcelona: Bosch, 1997. Medio impreso.

López, Ana María. «Early Cinema and Modernity in Latin América». Cinema Journal 40, 1 (2000). Medio impreso.

Machado, Arlindo. Pré-cinemas \& pós-cinemas. Campinas: Papirus, 2008. Medio impreso.

Musser, Charles. «At the beginning: Motion Picture production, representation and ideology at the Edison and Lumiere companies». The Silent Cinema Reader. Eds. Lee Grieveson y Peter Kramer. London and New York: Routledge, 2004. 15-30. Medio impreso.

Mouesca, Jacqueline. El documental chileno. Santiago: LOM Ediciones, 2005. Medio impreso.

Mouesca, Jacqueline y Carlos Orellana. Breve historia del cine chileno. Desde sus orígenes hasta nuestros dias. Santiago: LOM Ediciones, 2010. Medio impreso.

Paiva, Samuel y Sheila Schvarzman, orgs. Viagem ao cinema silencioso do Brasil. Rio de Janeiro: Azougue, 2011. Médio impreso.

Sadoul, Georges. Historia del cine mundial. Desde los orígenes. México: Siglo xxI, 2004. Medio impreso. 
Schvarzman, Sheila. «Travelogue e cavação no Brasil pitoresco de Cornélio Pires». Viagem ao cinema silencioso do Brasil. Orgs. Samuel Paiva y Sheila Schvarzman. Río de Janeiro: Azougue, 2011. 46-64. Medio impreso.

Stock, Ann Marie. «El cine mudo en América Latina: paisajes, espectáculos e historias». Historia general del cine. Volumen IV América (1915-1928). Coord. Jenaro Talens y Santos Zunzunegui. Madrid: Cátedra, 1997. 129-57. Medio impreso.

Vanoye, Francis y Anne Golio-Lété. Ensaio sobre a Análise Fúlmica. Campinas: Papirus, 2011. Medio impreso.

Vega, Alicia, Itinerario del cine documental chileno 1900-1990. Santiago: Universidad Alberto Hurtado, 2006. Medio impreso.

Veyre, Gabriel. «Cartas a su madre, julio 25 de 1896; agosto 16 de 1896; noviembre 6 de 1896; enero 15 de 1897; febrero 3 de 1896; mayo 17 de 1897. Comité para la conmemoración de los cien años del cine mexicano». Gabriel Veyre, representante de Lumière. Cartas a su madre. México: Filmoteca de la UNAM, 1996. Medio impreso. 